\title{
Cost-effectiveness of Dental Surgery Procedures: A Call for Strengthening the Evidence: Reply
}

\author{
Jane Maraka • Caris Grimes · Jaymie Henry • \\ Michael Cotton
}

Published online: 3 April 2014

(C) Société Internationale de Chirurgie 2014

We thank Benzian and Neiderman [1] for their comments regarding the lack of evidence for the cost-effectiveness of dental surgery in the literature in their response to our article [2]. Indeed, neglect of cases requiring immediate dental extraction is an important cause of sepsis in low- and middleincome countries (LMICs) which can ultimately be life threatening. As part of the International Collaboration of Essential Surgery, we believe that essential surgical procedures, defined as simple interventions that save lives and prevent disability, should be available and accessible to all, and that includes dental extraction for neglected caries.

We agree with their call for more cost-effectiveness studies to be done on tooth extraction to dispel the myths that surgical interventions are costly. We also call again for more studies to be done on the cost-effectiveness of other neglected simple surgical interventions for common disabling and life-threatening surgical conditions. We note an increasing interest in atraumatic restorative treatment for dental caries, which removes the need for drills, electricity, or running water and which has been specifically developed for LMICs [3]. Studies on comparative costs and benefits of this technique are also apposite.

We join with Benzian and Neiderman in calling for the inclusion of basic oral surgery in the armamentarium of Essential Surgeons.

\section{References}

1. Benzian H, Neiderman R (2014) Cost effectiveness of dental surgery procedures: a call for strengthening the evidence [letter]. World J Surg 38. doi:10.1007/s00268-014-2474-6

2. Grimes CE, Henry JA, Maraka J, Mkandawire NC, Cotton M (2014) Cost-effectiveness of surgery in low- and middle-income countries: a systematic review. World J Surg 38(1):252-263. doi:10.1007/s00268-013-2243-y

3. Frencken JE, Pilot T, Songpaisan Y, Phantumvanit P (1996) Atraumatic Restorative Treatment (ART): rationale, technique, and development. J Public Health Dent 56:135-140. doi:10.1111/j. 1752-7325.1996.tb02423.x
J. Maraka

East of England Deanery, Essex, UK

C. Grimes $(\bowtie)$

Kings Centre for Global Health, Kings College, London, UK e-mail: carisgrimes@ doctors.org.uk

J. Henry

University of California Berkeley School of Public Health,

Berkeley, CA, USA

J. Henry

Institute for Global Orthopaedics and Traumatology (IGOT),

San Francisco, CA, USA

M. Cotton

A\&E Department, University Hospital of Canton Vaud,

1011 Lausanne, Switzerland 